\title{
ESCRITA ACADÊMICA E CRITICIDADE ${ }^{1}$
}

\section{ACADEMIC WRITING AND CRITICISM}

\author{
Dina Maria Martins Ferreira² \\ Fazer ciência năo é apenas estabelecer-se \\ nos centros das abstraçóes, \\ que apenas privilegiam a razâo. \\ Ciência pode (e deve) ser \\ um modo de intervençâo no mundo [...] \\ (RAJAGOPALAN; MARTINS FERREIRA, 2006, p. 7). \\ Porquê pensar: [...] porque pensar não é tudo. \\ A lucidez das nossas açóes pressupóe \\ que elas sejam pensadas, \\ mas se forem só pensadas nunca serâo açōes. \\ É preciso agir e sentir porque o pensamento \\ só é útil a quem nâo se fica pelo pensar. \\ Aqueles que se arrogam a só pensar, \\ passam a vida a espalhar a morte no que escrevem, \\ a mesma morte que está dentro deles
}

(SANTOS, B., 2012, p. 40).

RESUMO: De uma maneira geral, o gênero acadêmico-científicos surge a partir da necessidade de se divulgar o conhecimento produzido através do método científico, com uma discussăo que exija também um arcabouço de discurso científico. No Brasil, a produçăo científica está intrinsecamente ligada à Universidade, especialmente, a pública, cuja produçâo e respectiva publicaçăo estăo vinculadas, boa parte, ao financiamento dado à pesquisa. Mas este quadro de 'perfeiçăo' científica é atravessado pela realidade da quantificaçăo, deixando, muitas vezes, o aspecto qualitativo de lado. A quantificaçăo ganha força, na medida em se a produtividade de um pesquisador também é avaliada pelo número de trabalhos apresentados ou publicados em eventos e revistas de grande relevância no âmbito científico, sem que se considere o impacto do trabalho na área de atuaçấo do seu autor. E a busca pelo cumprimento de metas numéricas, chamada por alguns de produtivismo, acaba se tornando mais importante que a relevância ou a criatividade dos conhecimentos que estăo sendo expostos através da escrita acadêmica. Sob a lâmina afiada entre quantificaçâo e qualificaçâo, apresentam-se, nestes estudos, indagaçōes de cunho ético e de sobrevivência enquanto pesquisador, ou seja, de exclusăo e de inclusăo do pesquisador no campo universitário.

$1 \quad$ Este artigo é parte de uma pesquisa maior, cujas modificaçôes e adequaçôes aqui ministradas visam atender às propostas da Revista Raído.

2 Pesquisadora do Centro de Atualidades e Cotidiano da Université Paris V, Sorbonne. Professora e pesquisadora do Programa de Pós-Graduaçâo em Linguística Aplicada, Universidade Estadual do Ceará. Autora de quatro livros, organizadora de quatro livros, capítulo de livros, artigos nacionais e internacionais. 
Palavras-Chave: quantificaçăo; qualificaçăo; escrita acadêmica; ética; produtivismo.

ABSTRACT: In general, the academic-scientific genre arises from the need to disseminate knowledge produced through the scientific methods, with a discussion that also requires a scientific discourse framework. In Brazil, the scientific production and publication thereof are linked, much, funding given to research. But this picture of scientific 'perfection' is crossed by the reality of quantification, leaving often the qualitative aspect aside. Quantifying gains strength, as the productivity of a researcher is also evaluated by the number of papers presented or published at events and highly relevant journals in the scientific world, without considering the impact of the work on the author area of operation. And the search for compliance with numerical targets, called by someone as productivism, turns out to be more important than relevance and creativity of knowledge being exposed through academic writing. Under the sharp blade of quantification and qualification, we present in this study, questions of an ethical nature and a survival as a researcher, i.e., exclusion or inclusion of the researcher in the university field.

Keywords: quantification; qualification; academic writing; ethics; productivism.

\section{INTRODUÇÃO}

Os gêneros acadêmico-científicos surgem a partir da necessidade de se divulgar o conhecimento produzido através do método científico. Logo, é imprescindível que a escrita acadêmica esteja sempre vinculada a uma finalidade específica, como trazer algum tipo de avanço para o meio científico: um novo objeto, um olhar criativo sobre um objeto já conhecido, uma metodologia inovadora, enfim, uma discussâo que exija sua exposiçáo através de gêneros que compóem o arcabouço do discurso científico (artigos, banners, dissertaçōes, teses, capítulos de livros, livros etc.). Ocorrendo dessa maneira, o resultado é uma produçăo escrita criativa que promove o desenvolvimento da ciência e o aprimoramento do meio acadêmico.

No Brasil, a produçáo científica está intrinsecamente ligada à Universidade, especialmente, a pública, o que significa que boa parte do financiamento dado à pesquisa é de origem estatal ou federal. Faz-se necessário, por isso, que os trabalhos de pesquisadores e instituiçóes mantidos pelo financiamento público sejam avaliados por órgáos responsáveis pelo desenvolvimento científico (tais como Capes, CNPq, Funcap, Fapesp, entre outros), para que se conheça a qualidade da produçăo acadêmica e se mensure os resultados dos investimentos realizados.

Porém, sabemos que, atualmente, a maneira mais utilizada pelos órgăos avaliadores para julgar a qualidade da produçăo é através da quantificaçăo, deixando o aspecto qualitativo, muitas vezes, nas măos das bancas de defesa ou de pareceristas de revistas e eventos. Assim, mede-se a produtividade de um pesquisador pelo número de trabalhos apresentados ou publicados em eventos e revistas de grande relevância no âmbito científico, sem que se considere o impacto do trabalho na área de atuaçâo do seu autor. A busca pelo cumprimento de metas numéricas em um dado período de tempo, chamada por alguns de "produtivism", torna-se entăo mais importante que a relevância ou a criatividade dos conhecimentos que estăo sendo expostos através da escrita acadêmica. Além disso, algumas práticas pouco éticas săo utilizadas por muitos pesquisadores 
para aumentar sua produtividade e alcançar as metas estabelecidas. Năo é tăo difícil observar casos em que o mesmo trabalho é publicado em eventos diferentes apenas com a alteraçăo do título, uma prática nâo condenável, mas questionável, a fim de cumprir metas de produtividade.

É evidente que tais práticas interferem profundamente na maneira como os pesquisadores interagem com suas pesquisas e, consequentemente, na maneira como a escrita acadêmica é produzida, haja vista o "campo" e o "habitus" em que esta escrita se insere (BOURDIEU, 1984), produzindo tensōes nos direitos do pesquisador. Assim, nosso artigo se propóe a uma análise de como essa prática avaliativa reorienta a escrita produzida na academia na medida em que afeta profundamente os pesquisadores, partindo da hipótese de que seu viés quantitativo remodela os objetivos da escrita, que passa a nâo ter como principais funçôes a produçăo e divulgaçăo do conhecimento científico, mas o 'atulhamento' do currículo Lattes, o que afasta de modo notório a escrita acadêmica de um ideal que poderia proporcionar um desenvolvimento científico mais substancial e significativo.

\section{TENSÕES NA PRODUÇÃO ACADÊMICA: HABITUS ACADÊMICO E UNIVERSO DO PAPEL}

Quando se fala em tensăo, temos de pensar que as questôes tensionais săo muitas vezes ocasionadas por determinado "campo"- no caso universitário -, que se articula pelo "habitus" (BOURDIEU, 1984) que ali habita - regras e normas comportamentais -, que, no caso deste estudo, se refere à dinâmica da produçăo de conhecimento, o produtivismo. E, neste "campo" comunidade acadêmica, direitos têm sido camuflados e impedidos de serem realizados. Ortega y Gasset (1967, p. 52) pondera que "eu sou eu e minhas circunstâncias", mas, no entanto, o que ele nos propóe náo é nos vitimizarmos, mas lutar para salvar nossas circunstâncias, pois "se năo salvo a ela, năo salvo a mim". Ao propor que devemos salvar nossas circunstâncias, Ortega y Gasset entende "salvar" como compreender os sentidos de nossas circunstâncias, como se as compreendendo pudéssemos melhor vivê-las e melhor ligá-las, no caso, à nossa prática científica: "para salvar a circunstância é preciso compreendê-la, ou seja, saber o que ela significa nela mesma, na sua unidade e em suas efetivas conexôes, em sua irredutibilidade, contudo na plenitude do seu significado em nossa vida, atualizando todas as suas virtualidades" (SANTOS, V, 1998/1999, p. 63).

E, para justamente compreendermos nossas circunstâncias no espaço acadêmico, vamos entrar em um universo conflituoso em que os caminhos do pesquisador se emaranham em uma rede cujos nós políticos oscilam de acordo com os ventos, ou seja, a postura ética do pesquisador que se movimenta entre o aprofundamento na produçáo do saber e seu direito de refletir, pensar e agir, em contrapartida às exigências lattianas ${ }^{3}$ que valoram o conhecimento pela quantidade de papéis publicados.

Muitos espaços acadêmicos priorizam a quantidade de produçăo sem levar em conta a qualidade exigida para se alcançar o universo da ciência. No Brasil, tivemos o lançamento em agosto de 1999 da Plataforma Lattes, sistema organizado pelo CNPq

O neologismo lattianas refere-se ao currículo Lattes. 
que visa gerenciar uma base de dados sobre os pesquisadores e suas produçôes. Tantas sáo as solicitaçôes numéricas de produçáo que o pesquisador, para atender às 'normas', pode estar abrindo mâo do aprofundamento do conhecimento. Como diz Waters (2006, p. 28), editor da Harvard University Press, ao explicar o que chama "eclipse do valor",

Entramos na regiăo sombria da pesquisa acadêmica, e agora as exigências de produtividade estăo levando à produçăo de um número muito maior de coisas sem sentido. Em épocas como esta, pesquisadores inescrupulosos e inebriados fazem alegaçóes falsas sob a aparência de serem interessantes, mas que săo também inverificáveis.

A voz cáustica de Waters sobre o que está ocorrendo no campo universitário se amplia ao valorar a produçâo de artigos:

O problema dos artigos ridículos publicados pelos estudos das humanidades foi em parte resultado do grande aumento do número de publicaçóes que se espera que eles próprios (e todos os acadêmicos) perpetrem em papel ou despejem uns sobre os outros, na forma de comunicaçóes em congressos. Esse quadro mostra um mundo todo errado, mas o problema náo se limita às humanidades. Estamos experimentando uma crise generalizada das avaliaçôes, que resulta de expectativas náo razoáveis sobre quantos textos um estudioso deve publicar. Náo estou dizendo que náo haja boas publicaçóes - isso está muito longe de ser o caso -, mas o que as boas publicaçóes têm de bom se perde em meio a tantas produçóes que săo apenas competentes e muitas mais que năo săo nem isso (WATERS, 2006, pp. 24-25).

Em outras palavras, é o que Gonçalves Filho (2007, p. 1) também afirma sobre a produçâo de livros: "o modelo que as universidades adotam para a publicaçâo de livros é o mesmo de uma fábrica de automóveis. Elas exigem produtividade, mas nâo exatamente qualidade". E em resenha sobre o livro tăo crítico e violento de Waters, outra voz critica a corrida que se estabelece pela publicaçăo:

corrida pela publicaçăo talvez jamais tenha sido tăo frenética quanto hoje. Pesquisadores e professores precisam alcançar o estrelato nas avaliaçōes de órgáos do governo, as universidades precisam obter conceitos e notas altas, programas de pós-graduaçâo precisam sustentar suas boas famas e tudo isso depende da produçáo dos docentes vinculados às instituiçôes. Os currículos, de preferência o Lattes, precisam estar muito bem recheados para que valham algo nessa competiçăo, daí uma explosâo de revistas ruins e livros que deveriam ter sido revistas. Um boom de obras organizadas com jeito de coletânea escolar, artigos feitos a partir de dissertaçôes de mestrado e teses de doutorado mal editadas, textos apressados, organizadores esbaforidos tentando aumentar um ou dois pontos na "carteira" (RIBEIRO, 2009, p. 2).

Mas pensamos que năo é só de gritos desesperados que se desconstrói o que vem ocorrendo com o pesquisador e a produçâo do conhecimento, porquanto os atuais gritos seriam a ponta do iceberg de um tsunami que já se anunciou há décadas pela voz de Bourdieu (1984). Só que agora está aparecendo que as águas turbulentas do tsunami estăo promovendo afogamentos, afinal Bourdieu (1984, p. 21) já proclamava que "náo se pode excluir que análise científica, ela mesma, venha a exercer um efeito de teoria própria a transformar a visâo comum do campo [acadêmico]" (traduçâo nossa4). Aliás, para este autor,

$4 \quad$ "On ne peut exclure que l'analyse scientifique elle-même vienne à exercer un effet de théorie propre à transformer la vision ordinaire du champ". 
o prestígio científico equivale a um efeito de oficializaçăo, de natureza semilegais: por isso, a criaçáo de classes de notoriedade internacional fundada sobre o número de citaçôes ou a elaboraçâo de um índice de participaçâo no jornalismo săo operaçóes semelhantes àquelas que os produtores de palmares realizam no seio do próprio campo (1984, p. 21, traduçăo nossa5) (itálicos acrescidos).

\section{ENTULHO DO SABER}

Tentando olhar para esta problemática por outras direçóes, convergentes e/ou divergentes, ela pode ser pensada por outros focos: o valor do sujeito pesquisador frente ao objeto pesquisado e sua importância para o crescimento da ciência com consequente atuaçăo social. Essa questăo se amplia se a quantidade alcança o entulho do saber.

Dois fragmentos discursivos săo as locomotivas de nossa argumentaçăo: um de Einstein (citado em TAGEBLATT, 2005) que aponta o desgosto diante do 'atulhamento de saber'; e outro de Rajagopalan (2003) que critica o linguista como um derramador de pérolas. Ambos os fragmentos, de alguma forma, comungam críticas sobre a questáo do amontoado, o primeiro atende a um espaço do saber mais amplo e o segundo a área dos estudos da linguagem:

(a) A comunidade dos pesquisadores é uma espécie de órgăo do corpo da humanidade. Esse órgáo produz uma substância essencial à vida que deve ser fornecida a todas as partes do corpo, na falta da qual ele perecerá. Isso náo quer dizer que cada ser humano deva ser atulhado de saberes eruditos e detalhados, como ocorre frequentemente em nossas escolas nas quais [o ensino das ciências] vai até o desgosto. Náo se trata também de o grande público decidir sobre questóes estritamente científicas. Mas é necessário que cada ser humano que pensa tenha a possibilidade de participar com toda lucidez dos grandes problemas científicos de sua época, mesmo se sua posiçăo social năo lhe permite consagrar uma parte importante de seu tempo e de sua energia à reflexăo científica. É somente quando cumpre essa importante missăo que a ciência adquire, do ponto de vista social, o direito de existir (EINSTEIN citado em TAGEBLATT, 2005, p.4) (itálicos acrescidos);

e

(b) A autoridade do linguista nâo é automaticamente aceita pela sociedade ampla. Ela precisa ser conquistada. E para conquistá-la é necessário usar bastante persuasăo. Náo é derramando o nosso saber - como se fosse um punhado de pérolas em meio a um amontoado de porcos ávidos - que vamos conseguir convencer o público leigo de que temos algo importante a dizer (RAJAGOPALAN, 2003, p. 8) (itálicos acrescidos).

No primeiro fragmento Einstein atualiza comentários que perfilam o pesquisador como um profissional que se perde na quantidade de saberes, os quais năo atuam na prática social; e, como tal, apenas preenchem dados quantitativos necessários para alçar o profissional à importância curricular solicitada pelo Olimpo acadêmico. No

$5 \quad$ "(...) le prestige cientifique équivaut, on vient de le voir, à un effet d'officialisation, de nature quasi juridique : ainsi, l'établissement de classes de notoriété internationale fondée sur le nombre de citations ou l'élaboration d'un indice de participation au journalisme sont des opérations tout à fait analogues à celles que réalisent, au sein même du champ, les producteurs de palmarès". 
segundo, Rajagopalan completa a problemática do quantitativo ao posicionar o saber na estratosfera dos eleitos que ignoram o saber do leigo; este autor levanta a questáo de a necessidade dos estudiosos ouvirem os leigos, já que ambos os sujeitos - pesquisador e leigo - compartilham a prática social em que convivem.

No que concerne ao produtivismo quantitativo, o sujeito acadêmico 'comum' é aquele que normalmente ainda năo desfila pelo tapete vermelho da Academia, que náo faz parte da casta nobre, e que, por tal, se encontra na massa de um agrupamento acadêmico cujos corpos se movimentam na multidāo de objetos do conhecimento valorados pela quantidade. Damos a esse acadêmico a valoraçâo de 'comum' nâo para aplaudir aqueles 'divinos', mas para salientar que nâo estamos atribuindo a todos os acadêmicos a postura que vamos discutir. Nessa valoraçấo, primeiramente estaria a quantidade de papéis, ou seja, o pesquisador passa a ser avaliado pelo volume de papéis que fabrica; escreve sob a ótica da paráfrase, pois há que enumerar multiplicando 'conhecimento', o que nos faz lembrar a piada de corredor em que o pesquisador ironicamente diz ao colega à sua frente: "-- se eu ganhasse na proporçăo de papéis que manejo, estaria rico". A segunda perspectiva do quantitativo é correlacionar a quantidade de escritos à quantidade de objetos de saber; a cada escritura, o pesquisador pensa estar criando múltiplos objetos de saber. No entanto, cada produçăo năo é necessariamente um novo objeto de saber, pode ser uma releitura do objeto. Barthes (1974) nos auxilia com a ideia de que cada releitura é uma primeira leitura, ou melhor, ressignificar um texto năo é obrigatoriamente apresentar um novo objeto, mas possivelmente reapresentá-lo sob nova ótica. Por esse foco, entramos na terceira valoraçăo do quantitativo, que se avoluma ao propiciar a cada objeto de saber novas representaçóes. $\mathrm{O}$ atulhamento do saber ganha um lamento frente a um desejo năo realizado:

A tese do representacionalismo ${ }^{6}$ é, ao mesmo tempo, uma lamentaçâo e uma expressáo de desejo. Ela é um gesto de lamentaçâo porque afirma a incapacidade dos seres humanos de apreenderem o mundo numenal ${ }^{7}$ tal e qual [...] Por outro lado, ela também é uma expressăo de um desejo, pois elege como condiçấo ideal da linguagem a total transparência (RAJAGOPALAN, 2003, p. 31) (itálicos acrescidos).

Apesar da questâo do representacionalismo se ater à teoria de linguagem, fazemos correlaçăo metafórica às múltiplas representaçôes que o pesquisador dá a seu objeto de pesquisa, que, para provê-lo de aparência de ciência, precisa de derivaçóes representacionais que se agrupam em montes aleatórios. Ele precisa de qualquer maneira que seu objeto se apresente, mas como essa epifania científica nem sempre é possível ou alcançada constrói ilusoriamente um amontoado de representaçôes. Derrida (1999) nos possibilita continuar em nossa metáfora ao oferecer o que chama de "metafísica da presença". Esse autor aplica a ideia de "metafísica da presença" à escritura, ou seja, nenhum texto pode aspirar a um sentido estável, pois o sentido está sempre em descentramento, na medida em que o rompimento entre significante e significado é constante, ou seja, pensamos que há uma essência do significado, quando apenas temos a ilusăo de sua presença. E podemos posicionar o pesquisador

\footnotetext{
$6 \quad$ Representacionalismo da/na linguagem leva à problemática da linguagem como atividade construtora de mundo versus a linguagem separada dos objetos do mundo. Ver Dascal (1983).

7 Expressăo noumenon, utilizada por Kant para determinar a coisa em si. Ver Kant (1978).
} 
nessa mesma dinâmica: ele pensa ser seu objeto de estudo o centro essencial do saber, mas, na realidade, tem à sua frente a ilusăo de sua presença, na medida em que nenhum objeto de saber pode aspirar a um significado estável, estando este em contínua reprodutibilidade sem uma identidade unitária e estável. E, nessa busca de eliminar sua representatividade e mostrá-lo em sua essência, pode estar criando um amontoado de representaçôes. Por essa situaçấo, é que formulamos que o desejo de apresentaçăo é o lamento das representaçōes.

Alguns pensadores, inclusive os referidos - Einstein e Rajagopalan -, lutam contra a postura do excesso do sujeito cientista. Mas parece-nos que este sujeito que se perde em seu amontoado de saber ou que derrama saberes em detalhamentos 'infinitos' está situado em um momento sócio-histórico. Ou melhor, em um contexto mais amplo, é necessário entender que o sujeito e seu objeto de saber estăo inseridos no momento da pós-modernidade, aquele em que "previamente vivido como tendo uma identidade unificada e estável, está se tornando fragmentado: composto năo de uma única, mas de várias identidades, algumas vezes contraditórias ou náo resolvidas" (HALL, 2000, p. 12). O que se pode aventar é que os sujeitos pesquisadores, por estarem na prática social (acadêmica) de uma pós-modernidade, portanto fragmentados, saem em busca de um essencialismo estratégico, que aporta na quantidade aleatória de um pretenso fazer científico. A ideia do excesso quantitativo junta fragmentos do saber que constrói um centro, mesmo que seja um centro 'atulhado'.

Em contexto mais específico, Sennett (2001) talvez nos dê argumentos de discussăo- e năo de justificativas para a persistência do 'atulhamento'. Para este autor, o sujeito pesquisador motivado cria expectativas - tais como divulgaçăo e reconhecimento- em relaçăo ao objeto pesquisado; como as expectativas nâo sâo atendidas, começa a adiar o resultado de suas expectativas; e de tanto adiar cai na fronteira do sujeito irônico, aquele que talvez só acumule papéis, objetos, representaçōes de objeto e até ironize em torno deles - uma forma etnocêntrica de se valorizar, pois reúne os objetos em um monte, um centro 'atulhado' mas nâo menos centro.

A força etnocêntrica do 'atulhamento' de saberes năo se encontra só em uma possível justificativa para satisfaçăo de expectativas e rearrumaçăo de fragmentaçôes em um centro-monte. $O$ etnocentrismo se faz presente na própria crítica contra o 'atulhamento' de saberes. Einstein (citado em TAGEBLATT, 2005) e Rajagopalan (2003) estăo presos ao etnocentrismo, na medida em que ao criticar o amontoado de saber, designam os pesquisadores como "substância essencial" e "pérola", respectivamente. A aporia se manifesta, pois, a crítica precisa do fetiche para combatê-lo: pesquisador e derramador de saber sofrem açâo de fetiche, pois săo representados no processo designativo como ídolos venerados - "substância essencial" e "pérola". Sem dúvida, săo designaçôes que ratificam a posiçăo etnocêntrica do cientista, cujas designaçôes precisam ser utilizadas na tentativa de romper o etnocentrismo. Tais designaçóes tentam deslocar o centro do saber pelo processo de transposiçăo (renversement)8 (DERRIDA, 1999), mas năo conseguem desconstruir a oposiçăo binária, já que năo basta apenas

8 Segundo Derrida(1999), renversement éapontar o que foirecalcado evalorizá-lo; a leitura desconstrutora propóe-se como leitura descentrada e, por isso mesmo, năo se reduz ao movimento de renversement, pois se estaria apenas deslocando do centro por inversăo, quando a proposiçâo radical é a de anulaçâo do centro como lugar fixo e imóvel. 
inverter a dessimetria, porquanto se continua nas oposiçóes binárias: pérola/porco e ciência/laico. Parece que as categorias - pérola/porco e ciência/laico - habitam a dimensăo da (in)discernibilidade, ou seja, (im)possibilidade de decidir entre o falso e o verdadeiro, entre o pior e o melhor, quando talvez a questăo entre Olimpo - pesquisadores - e Hades - leigos - seja uma questăo do que Derrida (1999) nomeia de 'indecidível', ou seja, marcas sâo inscritas sem posiçôes decidíveis e sem independência umas das outras.

É importante indicar, em nossa argumentaçâo, que năo estamos em nossas indagaçôes criando hostilidades entre nossos pares, pois "năo há nada verdadeiro, sábio, humano ou estratégico em confundir hostilidade à injustiça e à opressâo, [...] com hostilidade à ciência e à racionalidade, o que é uma tolice" (ALBERT, citado em SOKAL; BRICMONT, 1999, p. 13).

\section{TENTATIVAS CONCLUSIVAS E INDAGAÇÕES}

O leitor deve naturalmente estar se perguntando se os abusos de paráfrases, se o volume de produçâo sem inovaçăo de conhecimento "nascem de uma fraude consciente, de auto engano ou de uma combinaçăo de ambos" (SOKAL; BRICMONT, 1999, p. 20). Essas questóes específicas sobre atitude e intençōes de determinados pesquisadores năo sâo parte de nossa proposta. Nâo estamos no embate proposto por Sokal e Bricmont (1999) em relaçăo a intelectuais de renome. A nossa proposta é um 'pensar crítico' sobre a postura acadêmica do pesquisador năo apenas em relaçăo ao saber, mas também em relaçăo ao modelo de produtividade imposto pela Academia e à escrita resultante dessa prática.

Se o sujeito se encontra submerso nas tentativas de representaçăo, como fica o fazer conhecimento através da escrita? Será que o mundo da paráfrase nâo está criando uma estagnaçâo do conhecimento, ou seja, um universalismo antiprodutivo em que o paradigma epistêmico se assentaria? O termo "epistemicídios" (SANTOS, B., 2006a, p. 313) revela justamente um "paradigma epistemológico assente numa versâo extrema de universalismo antidiferencialista", em que as diferenças de conhecimento e de objetos de saber sâo excluídos em prol da hegemonia da quantidade de celulose escrita e da abstraçấo científica. O sistema inclusivo só admite a quantidade e abstraçăo teórica. De ambos os lados dizeres irônicos: - Publico, logo existo; Penso, logo teorizo.

Se nâo priorizarmos as hegemonias, optando pelo "renversement" (DERRIDA, 1999), talvez possamos chegar à "ecologia do saber" (SANTOS, B., 2006b) em que o convívio entre teoria e prática e entre o saber comum e saber científico se faz harmônico. Uma coisa é optar por um caminho (ou vários, quem sabe?), posiçâo que năo exclui, até pelo contrário, coloca o conhecimento no universo saudável das diferenças. Contestar e náo concordar com determinada posiçăo teórico-prática é admitir a diferença; negar sua existência é habitar o mundo do antidiferencialismo.

Uma outra perspectiva em prol do diferencialismo é pensar o "conhecimento sobre as condiçôes de possibilidade. As condiçôes de possibilidade da açăo humana projetada no mundo a partir de espaço-tempo local. Um conhecimento deste tipo é relativamente imetódico, constitui-se a partir de uma pluralidade metodológica" (SANTOS, B., 2006b, 
p. 77), ou seja, o pesquisador deve fazer da produçăo do conhecimento um percurso de inovaçăo, permitir-se a transgressóes metodológicas, cujo processo discursivo resulte em uma "personalizaçâo do trabalho científico" (SANTOS, B., 2006, p. 79). A paráfrase e o amontoado do saber ou só prática ou só teoria atendem ao estilo unidimensional, pois a dinâmica do conhecimento está na possibilidade diferencialista.

Parece-nos que essas brigas estăo muito mais para políticas de representaçăo tanto da identidade do sujeito acadêmico quanto do movimento do conhecimento. $O$ pesquisador se vê dentro de um stock identitário em que uma das identidades é assumida, ou de produzir papel, ou de estar no mundo da paráfrase, ou estar submisso a teorias, ou ser um livre pensador, ou ser um pensador comedido ou ter direito a uma pesquisa refletida, e assim por diante. E diante de tais identificaçōes acadêmicas, muitas vezes uma das identidades é reivindicada pelas circunstâncias do salve-se-quem-puder carreirista.

Podemos, entăo, equacionar esta questăo entre o pesquisador e a sua escrita como um jogo político de exclusâo e inclusâo. Se o pesquisador se mantém no centro da produçăo de paráfrase, dá-se a exclusăo do conhecimento, mas se o pesquisador náo aderir à quantidade pode ser ele o excluído. Săo as escolhas do pesquisador, as circunstâncias acadêmicas que vấo caucionar o que/quem se inclui/em e se exclui/em. O que se percebe é que esse movimento de inclusâo e de exclusăo no que tange ao pesquisador e à sua escrita é uma dinâmica política em que os fatores sâo determinados pelos interesses e habilidades de momento.

Sabemos ainda que a escrita acadêmica é direcionada principalmente pelos propósitos comunicativos dos gêneros utilizados no meio científico, por isso, se esse propósito é alterado, essa escrita sofrerá também mudanças significativas. Diante do que já discutimos, podemos afirmar que o propósito da escrita na Academia tem sido, muitas vezes, atender apenas às exigências produtivistas do Lattes, em funçăo de uma representaçăo do sujeito acadêmico para atender o habitus em que está inserido. Logo, năo nos surpreende que a escrita produzida dentro desse modelo esteja perdendo qualidade, carecendo de uma retomada do seu propósito primário - a construçăo, inovaçâo e divulgaçăo do conhecimento científico.

Eis o corredor que atravessamos no campo universitário, em que acadêmicos-pesquisadores-cientistas, ciência e vida se imiscuem em um embaralhamento que talvez possa representar o mundo acadêmico em que vivemos em nosso cotidiano. Esperamos que todo esse embaralhamento năo pare em uma "fábrica de automóveis" (GONÇALVES FILHO, 2007), que o "número de publicaçôes [năo se] perpetrem em papel" (WATERS, 2006, p.24) e que a "regiăo sombria da pesquisa acadêmica" (WATERS, 2006, p. 28) abra a porta para a luz do conhecimento. 


\section{REFERÊNCIAS}

BARTHES, R. Novos Ensaios Críticos: o grau zero da escritura. Săo Paulo: Cultrix, 1974. BOURDIEU, P. Homo Academicus. Paris: Minuit, 1984.

DASCAL, M. Pragmatics and Philosophy of Mind. Amsterdam: John Benjamins, 1983. DERRIDA, J. Gramatologia. Săo Paulo: Perspectiva, 1999.

GONÇALVES FILHO, A. O editor que nâo quer publicar pelo bem da ecologia, Lindsay Waters, da Harvard University Press, critica colegas acadêmicos e sugere maior rigor na hora de lançar um livro. Controvérsia Blog, pp.1-7, 16 de setembro de 2007. Disponível em: 〈www.controversia.com.br〉. Acesso em: 21 set. 2011.

HALL, S. A Identidade Cultural na Pós-Modernidade. Rio de Janeiro: DP\&A, 2000.

KANT, I. Crítica da razāo pura. Os Pensadores. Săo Paulo: Abril, 1978.

ORTEGA Y GASSET, J. Meditaciones del Quijote. Madrid: Allianza, 1967.

RAJAGOPALAN, K. Por uma Linguística Crítica: linguagem, identidade e a questăo ética. Sâo Paulo: Parábola, 2003.

; MARTINS FERREIRA, D. M. Políticas em Linguagem: perspectivas pragmáticas. Săo Paulo: Mackenzie, 2006.

SANTOS, B. de S. A construçâo intercultural da igualdade e da diferença. In: SANTOS, B. de S. A gramática do Tempo: para uma nova cultura política. Sâo Paulo: Cortez, 2006a, pp. 279-316.

Um Discurso sobre as Ciências. 4. ed. Săo Paulo: Cortez, 2006b.

Porquê pensar? In: SANTOS, B. de S. A Cor do Tempo quando Foge, v. 2. Coimbra: Almedina, 2012. pp. 39-40.

SANTOS, V. R. O homem e sua Circunstância: introduçâo à filosofia de Ortega y Gasset. Metavnoia. Săo Joăo del-Rey. 1, pp. 61-64, 1988/1989. Disponível em <www.ufsj.edu.br/ portal2respositorio/File/.../texto06_ortegaygasset.pdf>. Acesso em: 25 ago 2015.

SENNET, R. A Corrosáo do Caráter. Rio de Janeiro: Record, 2001.

SOKAL, A.; BRICMONT, J. Imposturas Intelectuais: o abuso da ciência pelos filósofos pós-modernos. Rio de Janeiro: Sáo Paulo: Record, 1999.

TAGEBLATT, B. Veja o que Einstein pensava sobre a relevância da divulgaçăo científica. Jornal de Ciência e Tecnologia, pp.1-4, agosto, 2005.

WATERS, L. Inimigos da Esperança: publicar, perecer e o eclipse da erudiçăo. Sâo Paulo: Ed. UNESP, 2006.Linguagem) - Universidade Estadual de Londrina, Londrina, 2012a. para entender, dentre outros aspectos, se a avaliaçâo vem ou nâo direcionando a abordagem do LDP aos eixos de ensino. 